\title{
Tendencias actuales de arquitectura de información en colecciones cartográficas digitales españolas
}

\author{
Beatriz González Suárez * \\ María Victoria Nuño Moral **
}

Artículo recibido:

10 de febrero de 2014.

Artículo aceptado:

9 de octubre de 2014.

\section{Resumen}

El objetivo principal del presente trabajo es realizar un análisis, tomando como punto de partida la Arquitectura de la Información (AI), de los sitios web de entidades que recogen material cartográfico anterior a 1901 en formato digital y lo difunden a través de Internet. Para ello se examinan aspectos relacionados con los siguientes ítems: Identidad e Información, Lenguaje y Redacción, Rotulado, Estructura y Navegación, Presentación de la Información, Búsqueda y Ayuda. Se pondrá de manifiesto cuáles son los puntos fuertes y débiles de cada entidad, reflexionando cuál ha de ser

* Centro de Información Cartográfico y Territorial de Extremadura, Consejería de Fomento, Vivienda, Ordenación del Territorio y Turismo, España. beatriz.gonzalezsuarez@gisvesa.com

** Universidad de Extremadura, España. mvnunmor@alcazaba.unex.es

INVESTIGACIÓN BIBLIOTECOLÓGICA, Vol. 29, Núm. 67, septiembre/diciembre, 2015, México, ISSN: 0187-358X. pp. 141-166 
la tendencia que deben tener las entidades cuyos resultados sean más negativos.

Para desarrollar dicha evaluación, se ha elaborado un cuestionario a partir de trabajos previos, adaptándolo a la muestra objeto de estudio. El análisis individual de cada organismo conlleva una valoración cualitativa de los resultados obtenidos, extrayendo las conclusiones más relevantes sobre los aspectos evaluados.

Palabras clave: Cartotecas Digitales; Arquitectura de la Información; Cartografía Histórica.

\section{Abstract}

Current information architecture trends in digitized cartography collections

Beatriz González-Suárez and María Victoria Nuño-Moral

This paper provides an analysis of the Information Architecture (IA) of websites of organizations devoted to assembling and disseminating collections of digitized nineteenth century maps. For this purpose, researchers examine the following website features: Identity and Information, Language and Usage, Labeling, Site Structure and Navigation, Display of Information, and Search and Help functions. This examination reveals both strengths and weakness of each website, while also underscoring how poorer performing websites might improve. A questionnaire designed in previous research and adapted to this sample was applied. The analysis of each organization provides a qualitative assessment of the data gathered, and relevant conclusions are drawn from aspects assessed.

Keywords: Digital Map Libraries, Information Architecture, Historical Maps.

\section{INTRODUCCIÓN}

T a Arquitectura de la Información (AI) se define como la ciencia o disci-

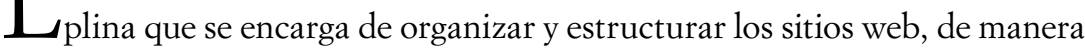
que el usuario pueda localizar, acceder y utilizar la información contenida en ellos (Pérez-Montoro Gutiérrez, 2010; Rosenfeld y Morville, 2002). 
Lo que hace que un sitio resulte atrayente para el usuario es el contenido que alberga. Para ello, es preciso clarificar aspectos tales como qué mostrar en cada página o sección, cómo agrupar el contenido, cómo mostrarlo, bajo qué etiquetas, etc. La AI se centra en todos estos factores con objeto de conseguir una proyección atractiva dirigida a los usuarios.

El usuario que entra en la página web de una cartoteca tiene necesidades muy específicas: quiere ver diferentes colecciones o mapas, o buscar documentos concretos de una forma ágil y sencilla. La máxima de la AI es que "todo esté donde se espera". Cuando esto no sucede, la experiencia del usuario y la usabilidad del sitio resultan negativos. Ambos aspectos están en relación directa con el diseño de las páginas, donde la AI se muestra como el factor determinante. Por este motivo, cualquier sitio, y entre ellos las cartotecas, han de proporcionar a los usuarios toda la información que pueda ser demandada y presentarla tal y como la quieren visualizar.

De forma generalizada, un arquitecto de la información será aquel profesional que, entre sus funciones, se dedique a refinar los objetivos del sitio, perfile la funcionalidad de los contenidos y diseñe cómo encontrar la información. Para ello, la AI se basa en una serie de componentes o sistemas, dependientes entre sí, que van a permitir descubrir y recuperar la información relevante de cada sitio web. Para tal fin, como base de su eficacia, ha de adoptarse el uso de un lenguaje o vocabulario normalizado, el cual articulará los diferentes sistemas que se describen a continuación:

1. A través de diferentes esquemas y estructuras, el sistema de organización se encargará de planificar y organizar los sitios para que resulten útiles. Los primeros se centran en agrupar y clasificar los ítems de información bajo un criterio (temático, cronológico o alfabético). Por su parte, las estructuras establecen las dependencias entre cada uno de los grupos establecidos anteriormente.

2. El sistema de etiquetado conceptualizará cada una de las opciones, grupos o enlaces que se utilicen en el sitio. El objetivo es que dichos rótulos o etiquetas supongan una representación mental del contenido que albergan.

3. El sistema de navegación debe permitir al usuario el desplazamiento por el sitio siendo imprescindible, al mismo tiempo, contar con un método de orientación. Con ello se evitará lo que se conoce como desbordamiento cognitivo. Dichos sistemas podrán ser globales (menús de navegación que están presentes en todas las páginas del sitio), locales (planificados para una página concreta) y contextuales (aquellos que permiten el desplazamiento entre los propios contenidos). 
4. El sistema de búsqueda deberá facilitar la localización y recuperación de aquello que demande el usuario. Tal y como señala Pérez-Montoro Gutiérrez (2010), su correcta implementación se basa en el equilibrio entre la información mostrada por resultado y la cantidad total de resultados recuperados.

A raíz de lo expuesto, el objetivo principal del presente trabajo es analizar las cartotecas digitales españolas desde el punto de vista de la AI.

\section{De LA CARTOGRAFía A LA CARTOTECA DIGITAL}

El concepto cartografía proviene del griego chartis, que significa mapa, y graphein, que significa escrito. De las distintas acepciones existentes destacamos la de la International Cartographic Association (ICA), que lo define como "el arte, la ciencia y la técnica de hacer mapas y su estudio tanto como documentos científicos como obras de arte, incluyendo todo tipo de mapas, cartas y secciones, modelos tridimensionales y globos que representan la Tierra o cualquier cuerpo celeste en cualquier escala" (Zentai, 2012: 7).

Por otro lado, la Organización de las Naciones Unidas define la cartografía como "arte y ciencia de la creación de una representación bidimensional de alguna parte de la superficie terrestre. Las características representadas pueden ser los objetos reales (mapas topográficos), o pueden ser conceptos y características más abstractas (mapas temáticos)" (ONU, 2000: 202). Finalmente, el Instituto Geográfico de Venezuela Simón Bolívar (2011: s. pág.), en su página web, habla del "arte de hacer mapas o como la técnica de confeccionar y representar sobre un plano todos los componentes del espacio terrestre, incluyendo las actividades y desarrollos del hombre".

Con base en estas definiciones, la cartografía se puede entender como la ciencia, arte y técnica de representar el territorio y sus particularidades. Cabe preguntarse entonces: ¿qué es un mapa? Al respecto, en la $17^{a}$ Asamblea General de la ICA se definía un mapa como

Una imagen simbolizada de la realidad geográfica que representa detalles o características seleccionados, el cual resulta del esfuerzo creativo de su autor a través de la ejecución de sus preferencias y que se diseña para ser utilizado cuando las relaciones espaciales son de relevancia primaria. (Hansen Albites, 2008: 9)

Como indica Fallas (2003: 1), un mapa es "la representación gráfica a una escala reducida de una porción de la superficie terrestre que muestra sólo al- 
gunos rasgos o atributos de la realidad". Así, los datos básicos recogidos en este documento son:

- Título.

- Fecha de la toma de datos y fecha de publicación del mapa.

- Leyenda: detalla la equivalencia entre la información recogida en un mapa y su representación en el mismo.

- Proyección y datum: información esencial para poder tratar y manipular un mapa en un sistema de información geográfica (Fallas, 2003).

- Escala: relación de proporción entre la realidad y las dimensiones en que está representada ésta en el mapa.

- Autor: persona o entidad que ha elaborado el documento.

- Fuente: indica si se ha redactado a partir de fuentes primarias (relatos de viajeros y exploradores, levantamientos de campo, imágenes de teledetección) o fuentes secundarias (elaborado a partir de otros mapas u otras fuentes documentales) (Hansen Albites, 2008).

Definidos los conceptos generales de cartografía y mapa, ¿qué se entiende por cartografía digital? Mientras que la cartografía analógica es la que se presenta en formato impreso y cuyo soporte más utilizado actualmente es el papel poliéster, ${ }^{1}$ la cartografía digital requiere, para su diseño, tratamiento y utilización, sistemas y programas asistidos por computadora (diseño asistido por ordenador o CAD), así como sistemas de información geográfica, infraestructuras de datos espaciales, etcétera.

La utilidad de la cartografía digital es muy variada, dependerá del contexto temático en el que se utilice y actúa, en conjunto, con muchas otras disciplinas del conocimiento. Esto es, no es una ciencia que actúe aisladamente. Según Marín Hernández y Vargas (2010: s. pág.),

[...] el impacto de los sistemas de información ha sido en múltiples ámbitos: usos de los SIG como herramientas e instrumentos para ayudar a la gestión pública y a los procesos de toma de decisiones, desarrollo de la geografía económica, cuestiones urbanas o racionalidad cartográfica en términos culturales, sociales y políticos [entre otros].

Siguiendo esta misma idea, Zentai (2012: 8) explica que "la función de los mapas ha cambiado considerablemente en la era digital: los mapas ya no son simples productos, sino más bien una colección especial de información

1 La norma usada actualmente en España que especifica las características que tiene que tener el papel cartográfico es la norma UNE 57.048-77, denominada Papel. Papel cartográfico para usos generales (AENOR, 2011). 
con un incremento en las funciones utilizando la base de datos que está detrás del mapa", entendido éste como una simple imagen en la pantalla de la computadora que esconde muchas más información "detrás" de lo que muestra la imagen.

A raíz de lo expresado anteriormente, la cartografía digital antigua puede ser entendida como el producto resultante de digitalizar y tratar informáticamente los mapas antiguos, en este caso aquellos anteriores a 1901. Se basa, por tanto, en escanear o fotografiar la cartografía antigua y manipularla para poder sacar el máximo rendimiento, ya sea ofreciéndola al usuario (misión principal) o incluyéndolas en Sistemas de Información Geográfica e Infraestructuras de Datos Espaciales (mediante georreferenciación, por ejemplo). Al estar ya editada y redactada es imposible la manipulación de los datos que recoge; por eso, la tendencia es emplear técnicas (utilizando recursos informáticos) que permitan obtener el máximo rendimiento de este tipo de documentos.

Para su descripción existen varios estándares que permiten, asimismo, el intercambio de información con otros organismos; entre ellos destacan los siguientes (cabe mencionar que las dos primeras normas están dirigidas a la descripción de documentos de carácter general, mientras que las restantes están orientadas a la descripción de información geográfica):

- ISBD (CM): norma de descripción bibliográfica e identificación de material cartográfico que asigna un orden a los elementos de la descripción y un sistema de puntuación para la misma. Se usa principalmente en bibliotecas.

- Dublin Core (Weibel y Koch, 2000): modelo de metadatos elaborado e impulsado por la Dublin Core Metadata Initiative (DCMI), que desarrolla y mantiene las especificaciones en apoyo de la descripción y normalización de recursos, permitiendo la descripción de todo tipo de recursos independientemente de su formato, área de especialización u origen cultural (Sánchez Maganto, Nogueras Iso y Ballari, 2008).

- ISO 19115:2003: norma de metadatos que define el esquema para describir la información geográfica y los servicios de ésta. Proporciona información acerca de la identificación, la medida, la calidad, el esquema espacial y temporal, la referencia espacial y la distribución de los datos geográficos digitales.

- Núcleo Español de Metadatos (NEM): establece un conjunto mínimo de metadatos recomendados para la descripción de recursos relacionados con la Información Geográfica (serie o producto completo, hojas o unidades, etc.) dentro de España (Sánchez Maganto, Nogueras Iso y Ballari, 2008). 
Por último, se hace referencia al concepto de cartotecas. A pesar de ser un término ampliamente utilizado, no aparece recogido en el Diccionario de la Real Academia Española de la Lengua. ${ }^{2}$ Por cartoteca se entiende el conjunto de documentos cartográficos, recogidos y tratados documentalmente por personal especializado para su posterior uso y difusión. Su razón de ser reside en la difusión de dicho material, bien sea de manera presencial o bien a través de Internet, de otra forma se convertirían en meros almacenes de documentos. Dicha difusión puede realizarse mediante facsímiles, microformas, diapositivas, etc.; no obstante, el método más utilizado hoy en día es mostrar la imagen en formato digital, a través de las colecciones que este tipo de centros ofrece en sus páginas webs.

Así, una cartoteca digital será aquel repositorio de ficheros en formato digital, que además de permitir o posibilitar la visualización y/o descarga de la imagen, aporte otra información sobre el documento, como pueden ser los metadatos o una descripción catalográfica (bien en formato ISBD, formato MARC o XML). Su creación permite al usuario, tanto especializado como general, consultar los catálogos y materiales del centro conservador, poniendo éstos a su disposición cuando lo requiera. Como manifiestan Fernández Wyttenbach y Bernabé Poveda (2011: 132. Las cursivas son nuestras.):

Las cartotecas virtuales son soluciones para acceder, vía Internet, a las colecciones de cartografía antigua distribuidas por las distintas bibliotecas y archivos mundiales [...]. El acceso a través de Internet a los fondos de las cartotecas, multiplica las aplicaciones que facilitan el trabajo de investigadores y documentalistas y promocionan la publicación y difusión del patrimonio cartográfico.

\section{Metodología}

El presente trabajo recoge la investigación, realizada entre los meses de octubre de 2013 y enero de 2014, centrada en los organismos que conservan cartografía histórica en formato digital, mediante el estudio de la Arquitectura de la Información (AI) de sus sitios web. Siguiendo la última edición de las Reglas de Catalogación, publicada en 1999, se ha considerado material cartográfico antiguo a aquel que es anterior a 1901.

Para el proceso de selección de las entidades se ha tomado como punto de partida el Directorio de cartotecas y colecciones cartográficas en instituciones españolas (Líter Mayayo, 2012) y el trabajo "Evaluación de las interfaces de

2 No obstante, se encuentran iniciativas por parte de autores como Luisa Martín Merás, que han solicitado la inclusión del término cartoteca en la $23^{a}$ edición del Diccionario de la Lengua Española (Blanco García, 2010). 
consulta de las Colecciones digitales patrimoniales españolas" (Sulé Duesa, Estivill Rius y Gascón García, 2011). Los filtros aplicados a la muestra seleccionada han sido los siguientes:

- Se limita a los organismos que muestran en Internet su material; es decir, que publican la imagen digital del documento.

- Se eliminan aquellos que son meros inventarios del contenido o catálogos automatizados de bibliotecas (OPAC).

- Se excluyen aquellos que no recogen material cartográfico, bien por la temática de sus contenidos o bien porque, a pesar de custodiar cartografía, ésta no es anterior a 1901.

- Los resultados de los archivos de la Corona de Aragón, del Archivo de la Real Chancillería de Valladolid, del Archivo General de Simancas, del Archivo Histórico Nacional y su Sección Nobleza y del Archivo Histórico Provincial de Álava quedan englobados en el Archivo General de Indias. El motivo es que en todos ellos la consulta de sus fondos se realiza a través del Portal PARES (Portal de Archivos Españoles, proyecto del Ministerio de Educación, Cultura y Deporte, http://pares.mcu.es/), de manera que los resultados obtenidos son extrapolables al conjunto mencionado.

- De igual forma, los resultados particulares de la Biblioteca Digital de Castilla la Mancha, la Biblioteca Virtual de Aragón, la Biblioteca Virtual de la Rioja, la Biblioteca Virtual del Principado de Asturias o la Biblioteca Virtual Sierra Pambley están comprendidos en la Biblioteca Regional de Madrid. En este caso, la razón es que han sido diseñados por la misma empresa (DIGIBIS. Aplicaciones y estándares al servicio de la sociedad del conocimiento, www.digibis.com), e igualmente, los resultados son extrapolables a todo el conjunto.

De esta manera, el conjunto de las 22 entidades que conforman la muestra queda representado en la Tabla 1.

Tabla 1. Listado de entidades que conforman la muestra analizada.

\begin{tabular}{|c|l|l|}
\hline id & \multicolumn{1}{|c|}{ Entidad } & \multicolumn{1}{c|}{ URL entidad } \\
\hline 1 & $\begin{array}{l}\text { Archivo de Villa. Ayuntamiento de } \\
\text { Madrid (Memoria de Madrid) }\end{array}$ & http://www.memoriademadrid.es/index.php \\
\hline 2 & $\begin{array}{l}\text { Archivo del Patronato de la Alham- } \\
\text { bray Generalife }\end{array}$ & http://www.alhambra-patronato.es/ria/handle/10514/16 \\
\hline 3 & Memoria Digital Vasca & http://www.memoriadigitalvasca.es/ \\
\hline 4 & $\begin{array}{l}\text { Universitat de Lleida (Fons } \\
\text { Sol-Torres) }\end{array}$ & http://soltorres.udl.cat/ \\
\hline
\end{tabular}




\begin{tabular}{|c|c|c|}
\hline 5 & Archivo General de Indias (PARES) & http://pares.mcu.es/ \\
\hline 6 & $\begin{array}{l}\text { Archivo Histórico Provincial de } \\
\text { Zaragoza }\end{array}$ & http://servicios3.aragon.es/opac/app/simple/ahpz \\
\hline 7 & $\begin{array}{l}\text { Archivo Real y General de Navarra } \\
\text { (Biblioteca Navarra Digital) }\end{array}$ & $\begin{array}{l}\text { http://www.navarra.es/home_es/Temas/Turismo+ocio+y+cul } \\
\text { tura/Archivos/Archivos/Archivo+General+de+Navarra/ (pági- } \\
\text { na del archivo) } \\
\text { https://administracionelectronica.navarra.es/binadi/busqueda. } \\
\text { aspx (página de la BND) }\end{array}$ \\
\hline 8 & $\begin{array}{l}\text { Arquivo do Reino de Galicia } \\
\text { (Galiciana) }\end{array}$ & $\begin{array}{l}\text { http://www.galiciana.bibliotecadegalicia.xunta.es/cartograf/gl/ } \\
\text { micrositios/inicio.cmd }\end{array}$ \\
\hline 9 & $\begin{array}{l}\text { Archivo General de la Región de } \\
\text { Murcia }\end{array}$ & http://archivoweb.carm.es/archivoGeneral/arg.inicio \\
\hline 10 & $\begin{array}{l}\text { Biblioteca Nacional de España } \\
\text { (Biblioteca Digital Hispánica) }\end{array}$ & $\begin{array}{l}\text { http://www.bne.es/es/Catalogos/BibliotecaDigitalHispanica/Ini } \\
\text { cio/index.html }\end{array}$ \\
\hline 11 & $\begin{array}{l}\text { Biblioteca Regional de Madrid } \\
\text { (Biblioteca Digital de la Comunidad } \\
\text { de Madrid) }\end{array}$ & $\begin{array}{l}\text { http://www.bibliotecavirtualmadrid.org/bvmadrid_publicacion/ } \\
\text { i18n/estaticos/contenido.cmd?pagina=estaticos/presentacion }\end{array}$ \\
\hline 12 & $\begin{array}{l}\text { Centro de Información Cartográ- } \\
\text { fica y Territorial de Extremadura } \\
\text { (Cartoteca Histórica Digital de } \\
\text { Extremadura) }\end{array}$ & http://217.124.180.27/dguot/Cartoteca/index.html \\
\hline 13 & $\begin{array}{l}\text { Institut Cartogràfic de Catalunya } \\
\text { (Cartoteca Digital) }\end{array}$ & http://cartotecadigital.icc.cat/ \\
\hline 14 & $\begin{array}{l}\text { Instituto de Cartografía de Anda- } \\
\text { lucía (Buscador de Cartografía } \\
\text { Histórica) }\end{array}$ & $\begin{array}{l}\text { http://www.juntadeandalucia.es/institutodeestadisticaycartogra } \\
\text { fia/cartoteca/buscar/search }\end{array}$ \\
\hline 15 & $\begin{array}{l}\text { Instituto Geográfico Nacional } \\
\text { (Fondos Cartográficos) }\end{array}$ & http://www.ign.es/fondoscartograficos/ \\
\hline 16 & $\begin{array}{l}\text { Instituto Geológico y Minero de } \\
\text { España }\end{array}$ & $\begin{array}{l}\text { http://www.igme.es/internet/sistemas_infor/carto/prin_index. } \\
\text { htm }\end{array}$ \\
\hline 17 & Real Academia de la Historia & $\begin{array}{l}\text { http://bibliotecadigital.rah.es/dgbrah/es/estaticos/contenido.cm } \\
\text { d?pagina=estaticos/presentacion }\end{array}$ \\
\hline 18 & $\begin{array}{l}\text { Universidad Autónoma de Madrid. } \\
\text { Departamento de Geografía } \\
\text { (Cartoteca "Rafael Mas") }\end{array}$ & http://biblioteca.uam.es/cartoteca/default.html \\
\hline 19 & Biblioteca Valenciana Digital & $\begin{array}{l}\text { http://bv2.gva.es/es/cms/elemento.cmd?id=estaticos/paginas } \\
\text { /inicio.html }\end{array}$ \\
\hline 20 & $\begin{array}{l}\text { Biblioteca Virtual del Patrimonio } \\
\text { Bibliográfico }\end{array}$ & $\begin{array}{l}\text { http://bvpb.mcu.es/es/estaticos/contenido.cmd?pagina=esta } \\
\text { ticos/presentacion }\end{array}$ \\
\hline 21 & $\begin{array}{l}\text { Biblioteca Digital de la Región de } \\
\text { Murcia }\end{array}$ & http://bibliotecadigital.carm.es/inicio/index.php \\
\hline 22 & Biblioteca Virtual de Andalucía & http://www.bibliotecavirtualdeandalucia.es/opencms \\
\hline
\end{tabular}

Fuente: elaboración propia

Para el análisis se establecieron una serie de variables cualitativas dicotómicas que se muestran en la Tabla 2. Para su elaboración se tomaron como punto de partida diferentes documentos y materiales. Cada vez es mayor el conjunto de obras que versan sobre evaluación de sitios web, la mayoría 
muestra diferentes listados de criterios a nivel general o con una aplicación específica.

Los primeros trabajos relevantes que se publican en relación con la AI en sitios web se remontan a finales de la década de los noventa. Dos de los trabajos pioneros son las metodologías expuestas por Caywood (1995) y Nielsen (1995). La plantilla de análisis que se utiliza en el presente estudio coincide con alguno de los aspectos presentados por el primer autor en lo relativo a condiciones de acceso (URL, navegadores, estándares), diseño del recurso y empleo de un lenguaje adecuado, entre otros elementos. Por su parte, el trabajo de Nielsen destaca por la evaluación de parámetros tales como la asistencia e información al usuario en operaciones de búsqueda y navegación o el uso de un lenguaje orientado al usuario.

Por su parte, del estudio de Ciolek (1996) es relevante la estructuración que ejemplifica en aspectos tales como la facilidad de acceso y el diseño aceptable del recurso y de sus contenidos, así como la presentación de la información o el lenguaje de la misma. En esta misma línea, aunque centrado en el ámbito bibliotecario, se sitúa el trabajo de Smith (1997), autor que agrupa un conjunto de "herramientas" para la evaluación de bibliotecas con objeto de ayudar al usuario al momento de evaluar la información encontrada en dichos centros. Olsina (1999) especifica en su tesis doctoral una relación de atributos que integran la metodología que el autor elabora en dicha investigación como método de evaluación de la calidad de sitios web.

Ya en la década siguiente se publica la obra de Jiménez Piano (2001), quien establece un cuestionario para sedes, instituciones públicas y privadas así como recursos de marcado carácter científico. Su trabajo coincide en los apartados referentes a empleo de URL claras e identificativas, actualización de recursos, sistemas de navegación y búsqueda, visualización en diferentes navegadores e identificación de propietario del recurso, entre otros temas. Cabe citar también la obra de Codina (2006) dadas las similitudes con algunos de los aspectos analizados en el presente estudio, tales como identificación de la autoría, público al que va dirigido el recurso, objetivos, actualización, cuestiones de navegación, rotulado y búsquedas, entre otros. Por último, la obra Thinking Critically about Web 2.0 and Beyond (Grassian, 2008) evalúa aspectos relativos a identidad e información sobre el recurso, fecha, registro de usuarios o facilidad de navegación.

Para el análisis realizado se ha adaptado la "Guía de Evaluación Heurística de Sitios Web” de Hassan Montero y Martín Fernández (2011) al ser el método que reúne un mayor número de elementos relacionados con los sistemas que conforman la AI. La plantilla utilizada ha sido modificada y adaptada al objeto de estudio que se pretende; por ejemplo, se ha incluido el bloque 
"Presentación de la Información”, cuyos elementos de análisis son pertinentes para los sitios web analizados.

El cuestionario aplicado a cada sede web recoge un total de 57 interrogantes, agrupados en 8 bloques, algunos de los cuales no son directamente cuantificables sino que son resultado de la visualización y evaluación del sitio web en su conjunto. De cada una de las entidades se ha realizado una evaluación intensa de distintos aspectos que abarcan los siguientes apartados:

1. Atributos Generales: objetivos, contenidos, servicios que ofrecen y diseño y estructura del sitio, además de coherencia y nivel de actualización de contenidos.

2. Identidad e Información: identidad corporativa y formas de contacto con la empresa, además de protección de datos y derechos de autor.

3. Lenguaje y Redacción: calidad de los contenidos textuales.

4. Rotulado: significación y familiaridad del rotulado de los contenidos.

5. Estructura y Navegación: estructura de navegación, de organización y uso de los enlaces hipertextuales.

6. Presentación de la Información: cómo se ofrecen los recursos visuales y qué permiten al usuario (descarga, impresión, metadatos).

7. Búsqueda: buscador del sitio y sus opciones.

8. Ayuda: documentación y ayuda contextual ofrecida al usuario para la navegación y consulta.

Tabla 2. Indicadores correspondientes al análisis heurístico.

\begin{tabular}{|l|}
\hline \multicolumn{1}{|c|}{ Atributos Generales } \\
\hline $1.1 \quad$ ¿Los objetivos del sitio web son concretos y bien definidos? \\
\hline 1.2 ¿Los contenidos y servicios que ofrece se corresponden con esos objetivos? \\
\hline $1.3 \quad$ ¿Tiene una URL correcta, clara y fácil de recordar? \\
\hline $1.4 \quad$ ¿Las URL de sus páginas internas son claras y permanentes? \\
\hline 1.5 ¿Muestra de forma precisa y completa qué contenidos o servicios ofrece realmente el sitio web? \\
\hline $1.6 \quad$ ¿La estructura general del sitio web está orientada al usuario? \\
\hline 1.7 ¿Es coherente el diseño general del sitio web? \\
\hline 1.8 ¿Indica el sitio web cuándo se actualiza? \\
\hline 1.9 ¿Se presenta la página en varios idiomas? \\
\hline 1.10 ¿Es compatible el sitio web con los navegadores? \\
\hline 1.11 ¿La página admite publicidad? \\
\hline 1.12 ¿El recurso tiene presencia en las redes sociales? \\
\hline 1.13 ¿Tiene sindicación de contenidos? \\
\hline 1.14 ¿Se exponen claramente los servicios que son gratuitos y los que no? \\
\hline
\end{tabular}


2.3 El logotipo, ¿es significativo, identificable y suficientemente visible?

2.4 ¿El logo enlaza con la página de inicio?

2.5 ¿Se ofrece algún enlace con información sobre la empresa, sitio web, webmaster, etc.?

2.6 ¿Se proporcionan mecanismos para ponerse en contacto con la empresa?

2.7 ¿Se proporciona información sobre la protección de datos de carácter personal de los clientes o los derechos de autor de los contenidos del sitio web?

2.8 ¿Es necesario registrarse para acceder a alguna parte del recurso?

2.9 ¿Existe algún formulario para recoger la opinión del usuario?

\section{Lenguaje y Redacción}

3.1 ¿El sitio web habla el mismo lenguaje que sus usuarios?

3.2 ¿Emplea un lenguaje amigable, familiar y cercano?

Rotulado

4.1 Los rótulos, ¿son significativos?

4.2 ¿Usa rótulos estándar?

4.3 ¿Usa un único sistema de organización, bien definido y claro?

4.4 ¿Utiliza un sistema de rotulado controlado y preciso?

4.5 El título de las páginas, ¿es correcto y ha sido planificado?

\section{Estructura y Navegación}

5.1 ¿Los enlaces son fácilmente reconocibles?

5.2 ¿La caracterización de los enlaces indica su estado (visitados, activos, etc.)?

5.3 ¿Todos los enlaces llevan a alguna página con contenido?

5.4 ¿Existen en cada página botones de enlace con la página siguiente y la anterior?

5.5 ¿Existen elementos de navegación que orienten al usuario acerca de dónde está (breadcrumbs o botón de inicio)?

5.6 ¿Tiene el sitio un site map o un buscador para quienes deseen acceder directamente a los contenidos sin tener que navegar?

5.7 ¿Las imágenes enlace incluyen un atributo title describiendo la página de destino?

5.8 ¿Todas las páginas enlazan con otras páginas?

5.9 ¿Incluye una visita guiada virtual?

5.10 ¿Incluye enlaces a sitios externos?

\section{Presentación de la Información}

6.1 ¿Se presentan los recursos visuales como ficheros de texto (PDF, DOC, TXT)?

6.2 ¿Se presentan los recursos visuales como ficheros de imagen (JPG, TIFF)?

6.3 ¿Permite la descarga y/o impresión de las imágenes?

6.4 ¿Se incluyen los metadatos de las imágenes?

6.5 ¿Aportan las imágenes algún valor añadido como, por ejemplo, georreferenciación de las mismas?

6.6 ¿Las imágenes incluyen marcas de agua como protección?

6.7 ¿Se presenta el contenido en otros formatos (CD-ROM, impreso, etc.)?

\section{Búsqueda}

7.1 ¿Se encuentra fácilmente accesible y reconocible como tal?

7.2 ¿Permite la búsqueda avanzada?

7.3 ¿Muestra los resultados de la búsqueda de forma comprensible para el usuario?

7.4 ¿Asiste al usuario en caso de no poder ofrecer resultados para una consultada dada?

7.5 ¿Utiliza lenguajes documentales controlados (lista palabras clave, tesauros, encabezamientos de materia)? 


\begin{tabular}{|l|}
\hline $7.7 \quad$ ¿Permite acceder a las últimas búsquedas? \\
\hline 8.1 ¿Posee una sección de Ayuda? \\
\hline $8.2 \quad$ El enlace a la sección de Ayuda, ¿está colocado en una zona visible y "estándar"? \\
\hline $8.3 \quad$ ¿Posee una sección de Frequently Asked Questions? \\
\hline
\end{tabular}

Fuente: elaboración propia

Finalmente, tras el análisis individual de cada una de las 22 entidades, se procedió a examinar los resultados obtenidos por todo el conjunto. Para su exposición y, como consecuencia, la posterior extracción de conclusiones generales, se han asignado valores al cumplimiento o no de los distintos aspectos, donde $1=\mathrm{SÍ}$ (indica que cumple el indicador) y $0=\mathrm{NO}$ (no lo cumple).

\section{Resultados}

En la primera columna del margen izquierdo aparecen los 8 bloques básicos en que se han agrupado los parámetros analizados, indicando entre paréntesis el número de ítems que se evalúan en cada uno de ellos de los 57 establecidos en total (reflejados en la Tabla 2). La primera fila representa el número asignado a cada una de las 22 entidades evaluadas (mostrado en la Tabla 1). Los resultados del análisis realizado se muestran en la última fila de la Tabla 3 ("Totales"). 


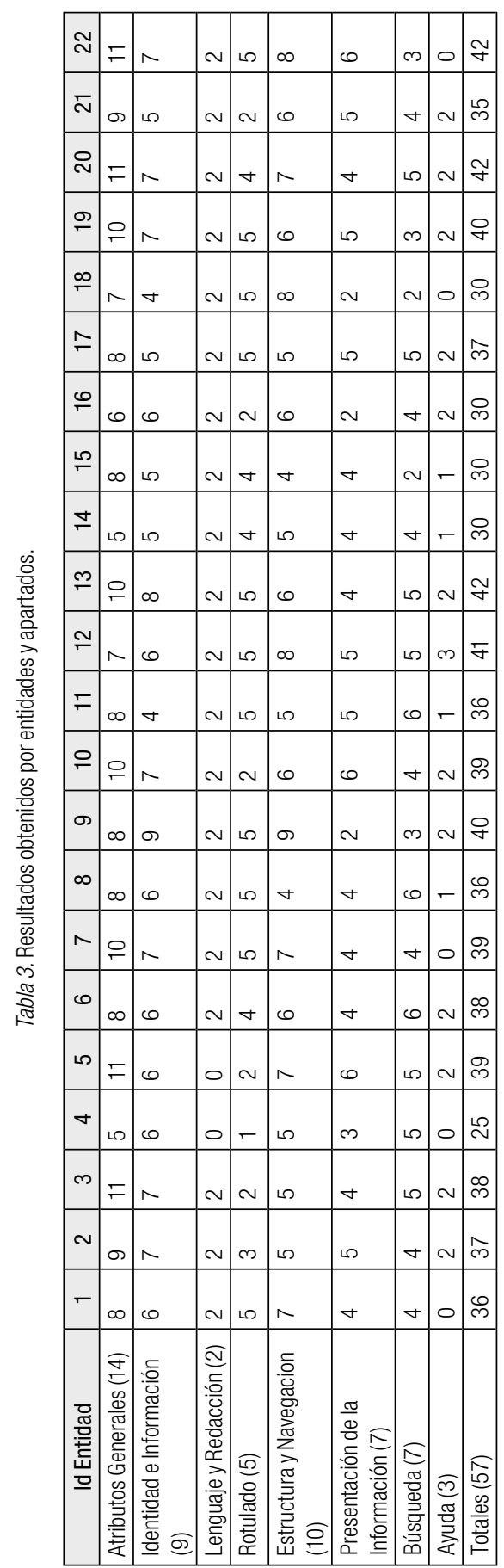

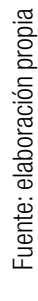


Los aspectos más relevantes a destacar de cada uno de estos ocho bloques son los que se exponen a continuación.

\section{Atributos Generales}

En la mayoría de los sitios web existe una correspondencia precisa y bien definida entre la presentación de objetivos y los contenidos y/o productos que ofrecen; se cuida igualmente tanto la estructura general como la coherencia en el diseño de las portadas y páginas internas. Entre los aspectos a mejorar se enumeran los siguientes:

- El uso de URL internas permanentes y que tengan una fácil memorización, lo que se denomina URL "semántica"; es decir, aquella que representa fielmente el contenido y temática del sitio web y que además resulta fácil de recordar por parte del usuario.

- Indicar tanto la fecha de creación como la de actualización de los contenidos, lo que aportaría una mayor credibilidad al sitio web.

- La traducción del recurso a otros idiomas (como mínimo al inglés), especialmente aquellos que están integrados en redes tales como Europeana, compuesta por numerosas instituciones culturales europeas.

- Presencia en las redes sociales, hecho que garantizaría la difusión (noticias, materiales que se custodian, etc.) a un mayor número de usuarios. Asimismo, debería revisarse el tema de la sindicación de contenidos con objeto de mantener informado al usuario de todas las novedades que se introduzcan en el recurso web.

Gráfico 1. Resultados obtenidos en el apartado Atributos Generales

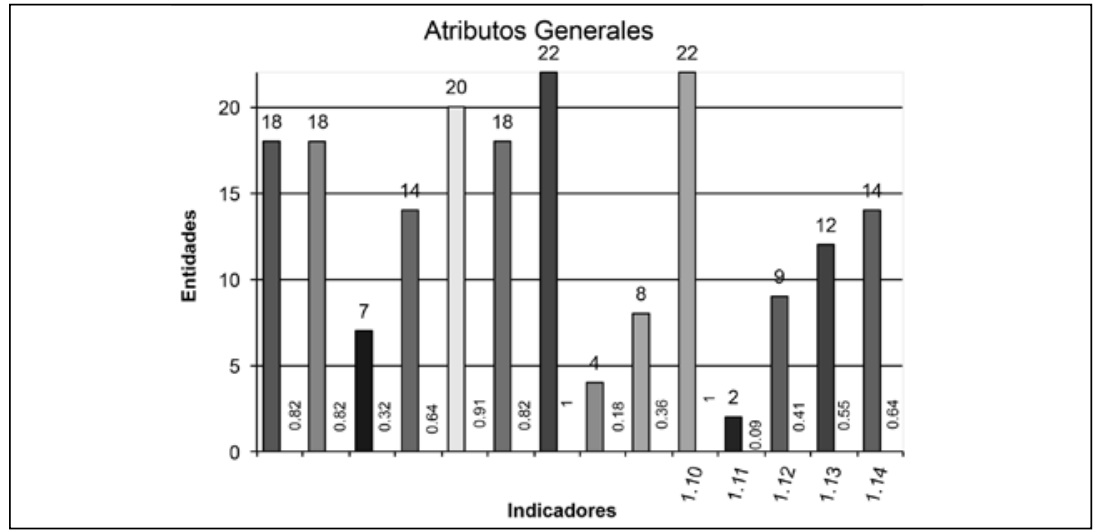

Fuente: elaboración propia 
Tal y como refleja el Gráfico 1, mientras que el $100 \%$ de las entidades analizadas muestran un diseño coherente con el contenido que muestran (1.7) y son compatibles con cualquier navegador (1.10), sólo el $9 \%$ incluyen publicidad dentro de sus páginas (son la Biblioteca Digital Hispánica y los fondos cartográficos del Instituto Geográfico Nacional). Asimismo, son sólo cuatro las instituciones que indican cuándo se actualizan los contenidos, servicios, etc.: Memoria Digital Vasca; la Biblioteca Virtual del Patrimonio Bibliográfico, que aunque no tienen fecha de actualización, en su portada aparecen noticias de cierta actualidad; el Archivo Histórico Provincial de Zaragoza (la única que tiene una fecha de actualización como tal) y la Biblioteca Digital de la Región de Murcia (aunque no pone la fecha de actualización, aparece la fecha del día en curso).

\section{Identidad e Información}

La mayoría de las entidades utilizan un logotipo y un tagline para identificar de manera clara tanto al recurso como a su contenido. Ofrecen información sobre la entidad o sitio web al mismo tiempo que proporcionan mecanismos de contacto. En cuanto a los aspectos a revisar destacarían:

- Uso del logotipo como anclaje a la página de inicio, lo cual ayudaría al usuario a deshacer la navegación cuando así lo precise. Este indicador sólo se encuentra en la mitad de los organismos analizados.

- Algunas entidades carecen de la información relativa a la protección de datos personales y/o derechos de autor del sitio.

- Se carece de un registro de usuarios a la hora de acceder a los contenidos. Requerir una inscripción por parte del usuario permitiría a la entidad desarrollar estudios sobre el tipo de visitantes que accede al recurso, el tipo de búsquedas que realiza, computar el número de accesos, etc., todo ello con el fin de mejorar el sitio web de la entidad.

- En relación con el aspecto anterior, igualmente sería recomendable que se incluyese algún formulario para recabar las quejas y/o sugerencias de los usuarios.

Como muestra el Gráfico 2, la mayor parte de las entidades ofrecen a los usuarios información relativa a la institución en la que se encuentran y además cuentan con la posibilidad de ponerse en contacto con dicho organismo. Sin embargo, resulta curioso que sólo tres entidades (Fons Sol-Torres, el Archivo Real y General de Navarra y el Archivo General de la Región de Murcia) cuenten con un formulario como mecanismo para recoger la opinión de sus usuarios. 


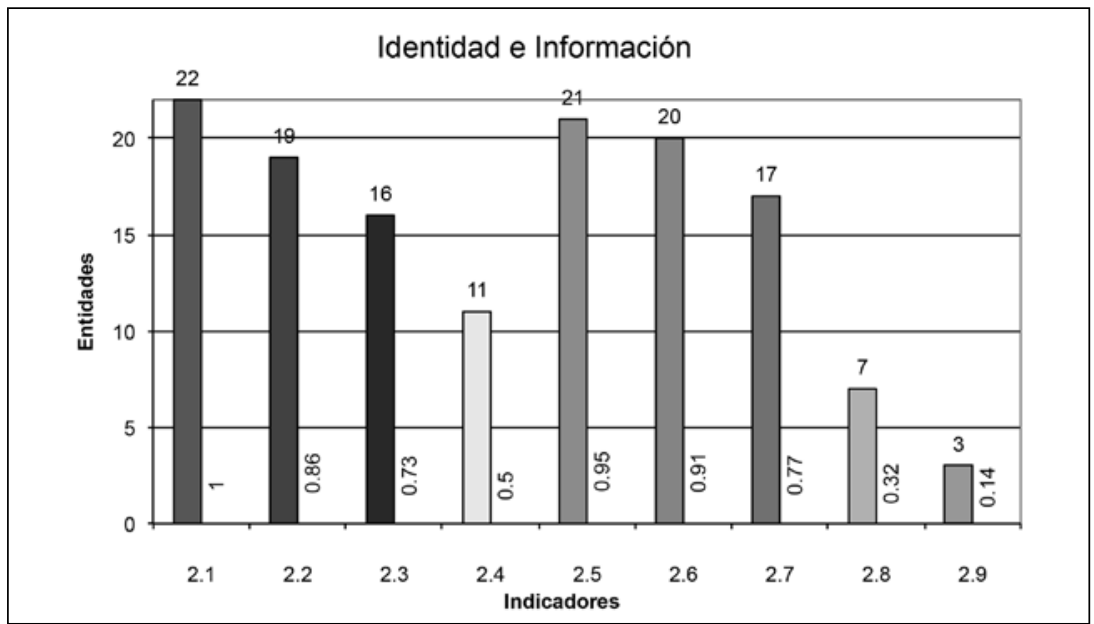

Fuente: elaboración propia

\section{Lenguaje y Redacción}

El resultado obtenido en ambas cuestiones ha sido el mismo. Como refleja el Gráfico 3, este apartado se cumple satisfactoriamente en todas las entidades excepto Fons Sol-Torres y Portal de Archivos Españoles (PARES), ya que, en la práctica, el usuario que visita estos sitios tiene una formación y/o conocimientos mínimos de la temática del recurso, por lo que los tecnicismos empleados no son tales, sino más bien términos de esa ciencia en cuestión. De este aspecto dependerá que un usuario siga acudiendo a un sitio web o, por el contrario, desista ante cualquier primer impedimento, en este caso, lingüístico.

En Fons Sol-Torres encontramos que la interfaz de usuario es complicada en cuanto a la búsqueda y uso del lenguaje. Más que un mal uso del lenguaje existen barreras lingüísticas como son el uso del inglés y del catalán, lo que limita al usuario a la hora de la navegación y búsqueda. Por su parte, en el PARES se utilizan términos demasiado técnicos y específicos de las ciencias documentales, como signatura, índices de descripción, signatura exacta, signatura incompleta, estrategias de búsqueda, etc. que sí pueden desorientar al usuario. 


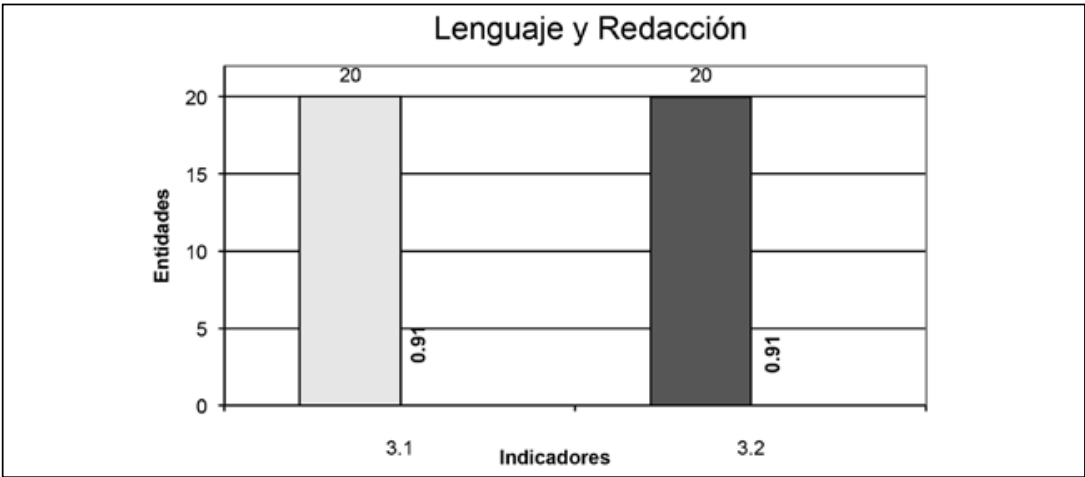

Fuente: elaboración propia

\section{Rotulado}

La mitad de las entidades cumplen el $100 \%$ de los indicadores establecidos. Se emplean etiquetas significativas y estándar para cada opción o tarea, utilizando un sistema de rotulado controlado y preciso, así como un único sistema de organización bien definido. Además presentan una equivalencia entre el título de la página principal y el título del elemento title del código fuente, siendo éste muy importante ya que es lo primero que verán los usuarios cuando entren en la página, por lo que debe aportar información concreta y precisa de lo que almacena el recurso. El $50 \%$ restante debería revisar este aspecto con el objetivo de no inducir a error y/o desorientar al usuario en la navegación y consulta.

\section{Gráfico 4. Resultados obtenidos en el apartado Rotulado}

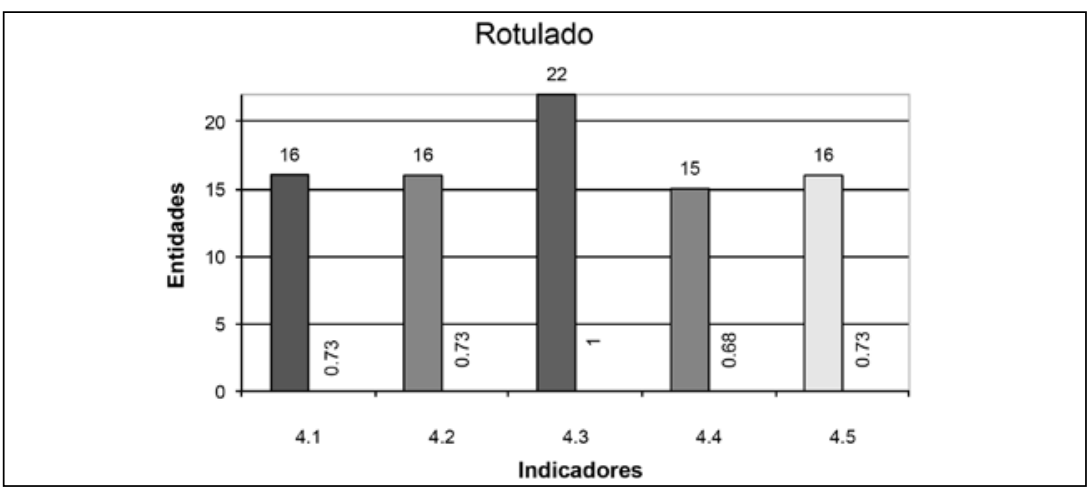


La relación y vinculación existente entre los interrogantes 4.1 (rótulos significativos), 4.2 (rótulos estándar) y 4.4 (sistema de rotulado preciso y controlado) queda patente en los resultados que refleja el Gráfico 4 . Un $73 \%$ de las entidades analizadas emplean rótulos significativos y que expresan algún concepto definido.

El $27 \%$ restante utiliza rótulos que desorientan al usuario, como en el caso de Memoria Digital Vasca y Fons Sol-Torres por la misma razón expuesta en el bloque anterior. El uso de un idioma extranjero limita el usuario visitante, y si se emplea en rótulos que aluden a tareas, dificulta que pueda interactuar con el sistema. Si no se utilizan rótulos estándar y significativos, el usuario se puede sentir perdido y desorientado durante la navegación y consulta.

El PARES tampoco cumple este parámetro por el uso de tecnicismos en algunos de sus rótulos. La Biblioteca Digital Hispánica, al tener una estructura orientada a la organización, emplea rótulos orientados a definir sus procedimientos internos. El Instituto Geológico y Minero de España (IGME) muestra bajo distintos rótulos los mismos contenidos (la colección, catálogos y biblioteca digital recogen los mismos fondos), por lo que orienta erróneamente al usuario durante su búsqueda. Por último, la Biblioteca Digital de la Región de Murcia también utiliza rótulos que inducen a confusión. La opción "Búsqueda por contenido" conduce al usuario a un cuadro de búsqueda y a un conjunto de enlaces a documentos seleccionados de diversa tipología y temática; bajo el rótulo "Búsqueda en catálogo" aparece una pantalla con opciones de búsqueda avanzada.

\section{Estructura y Navegación}

Llama la atención que en este apartado sólo un 14 \% de los organismos caracterice sus enlaces (principalmente con un cambio de color) una vez que han sido activados. Este factor ayuda, sin duda, a evitar la desorientación por parte del usuario. También se ha constatado la carencia de páginas huérfanas (páginas sin contenido) en el $100 \%$ de la muestra; lo que sí se ha detectado son enlaces inexactos en cuanto a errores técnicos o bien que no realizaban la función establecida. Igualmente, dicho porcentaje se refleja en la presencia de elementos de navegación que orientan al usuario, como son breadcrumbs, botones de avance y retroceso en páginas internas y enlace del logo con la página de inicio.

Así, los aspectos que presentan peor valoración y deberían ser revisados son: 
- Inclusión de un mapa web o un buscador interno para poder acceder directamente a los contenidos sin tener que navegar.

- Establecer enlaces a sitios externos. Sería recomendable insertar enlaces a sitios oficiales relativos a la misma temática, fuentes similares localizadas en diferentes puntos geográficos, etc.

- Revisar el atributo title de las imágenes del recurso, ayudando así a los motores de búsqueda a encontrar dicho recurso de forma más rápida y, como consecuencia, conseguir un mejor posicionamiento en los resultados de una consulta.

Gráfico 5. Resultados obtenidos en el apartado Estructura y Navegación

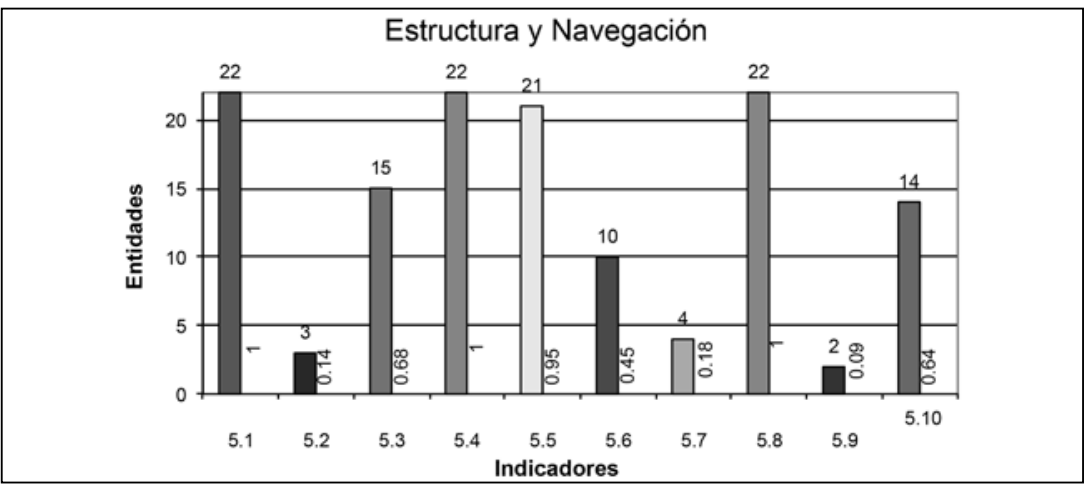

Fuente: elaboración propia

Los datos mostrados en el Gráfico 5 ponen de manifiesto que las cartotecas tienen como finalidad funcional ayudar en la localización y orientación del usuario, tal y como se desprende de los resultados obtenidos en los parámetros 5.1 (enlaces reconocibles), 5.4 y 5.8 (elementos de orientación). Resulta también llamativo que sólo el $9 \%$ de los sitios web evaluados (PARES y el Archivo General de la Región de Murcia) incluye una visita guiada virtual de sus instalaciones o de sus contenidos.

\section{Presentación de la Información}

El Gráfico 6 pone de manifiesto que todas las entidades ofrecen los recursos digitales en formatos que permiten su correcta visualización (mayoritariamente JPG y, en segundo lugar, PDF). Asimismo, la mayoría de las entidades permiten la descarga y/o impresión de las imágenes (sólo se han encontrado dos entidades que no posibilitan esta opción: Arquivo do Reino de Galicia (Galiciana) y el Instituto Geológico y Minero de España). 
Un alto porcentaje de las entidades ofrecen descripciones normalizadas de sus registros siendo los estándares utilizados para la descripción las normas ISBD, MARC, ISO 19115, METS, Dublin Core y EDM (Europeana Data Model). Igualmente, la mayoría de los materiales que conservan se han presentado en otros formatos tales como la edición de publicaciones impresas (catálogos, inventarios), exposiciones, etcétera.

Los resultados más bajos se han localizado, por un lado, en el uso de marcas de agua (sólo aparecen en un $50 \%$ de las entidades analizadas), considerado éste un elemento de protección de los derechos de uso y difusión sobre la imagen; por otro, en el manejo de elementos que permitan un mayor aprovechamiento de los recursos más allá de la simple visualización.

Gráfico 6. Resultados obtenidos en el apartado Presentación de la Información

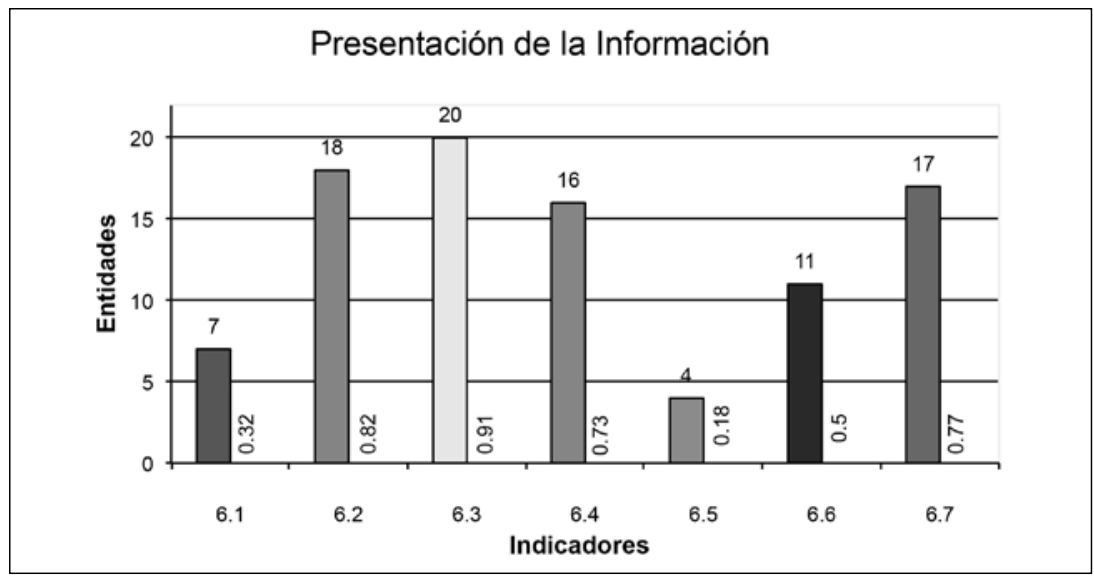

Fuente: elaboración propia

\section{Búsqueda}

Todos los sitios web disponen de un sistema de Búsqueda identificable, cuyos resultados se presentan de manera comprensible para el usuario. No obstante, no todas las entidades lo ubican en el mismo sitio, habiéndose encontrado el cuadro de búsqueda en la parte superior izquierda (Memoria de Madrid, Fons Sol-Torres o la Biblioteca Digital de la Comunidad de Madrid), en la parte inferior de la página (Archivo del Patronato de la Alhambra y Generalife) o en el centro de la misma (Histórico Provincial de Zaragoza o el Arquivo do Reino de Galicia, Galiciana), entre otras. De las 22 entidades 18 cuentan con la opción de búsqueda avanzada. Por su parte, el uso de lenguajes documentales (lista de palabras clave, tesauros, encabezamientos de 
materia) sólo es posible en 9 entidades mientras que la presencia de índices y/o clasificaciones (temáticas, geográficas, cronológicas) se registra en 17 organismos.

Como muestra el Gráfico 7, el principal aspecto que debe someterse a revisión es el relacionado con la asistencia al usuario (7.4) ante la falta de resultados. Sólo una entidad (Institut Cartogràfic de Catalunya) cumple dicha función; el resto se limita a "informar" de la inexistencia de resultados, sin ofrecer alternativas. Otro aspecto que debe ser considerado es el de permitir al usuario el acceso directo a las últimas consultas realizadas, ya que sólo un $23 \%$ dispone de dicha opción.

En este bloque destaca el sitio web del Instituto Geográfico Nacional ya que no tiene un cuadro de búsqueda como tal, sino que cuenta con tres opciones para realizar una consulta: Búsqueda geográfica, Búsqueda por texto y Búsqueda por entidades geográficas (que no se recojan en el primer tipo de búsqueda).

\section{Gráfico 7. Resultados obtenidos en el apartado Búsqueda}

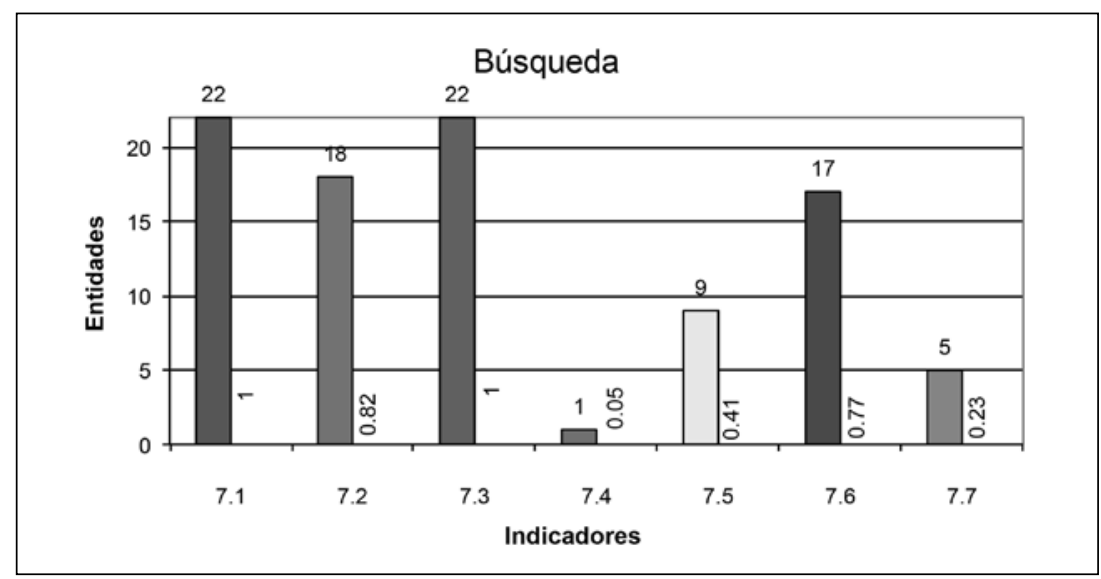

Fuente: elaboración propia

\section{Ayuda}

Por último, el Gráfico 8 revela que sólo 17 entidades poseen una sección de Ayuda, siendo una iniciativa necesaria para guiar al usuario en las distintas tareas y opciones que presentan. De ellas, 12 la ubican generalmente en la parte superior derecha de la página; el resto la sitúan en lugares menos habituales. En cuanto a las Frequently Asked Questions, sólo se ha encontrado en dos entidades: Cartoteca Histórica Digital de Extremadura y Memoria Digital Vasca. 
Desde una perspectiva negativa, cabe mencionar que la Biblioteca Virtual de Andalucía y Fons Sol-Torres no poseen Ayuda ni Frequently Asked Questions.

Gráfico 8. Resultados obtenidos en el apartado Ayuda

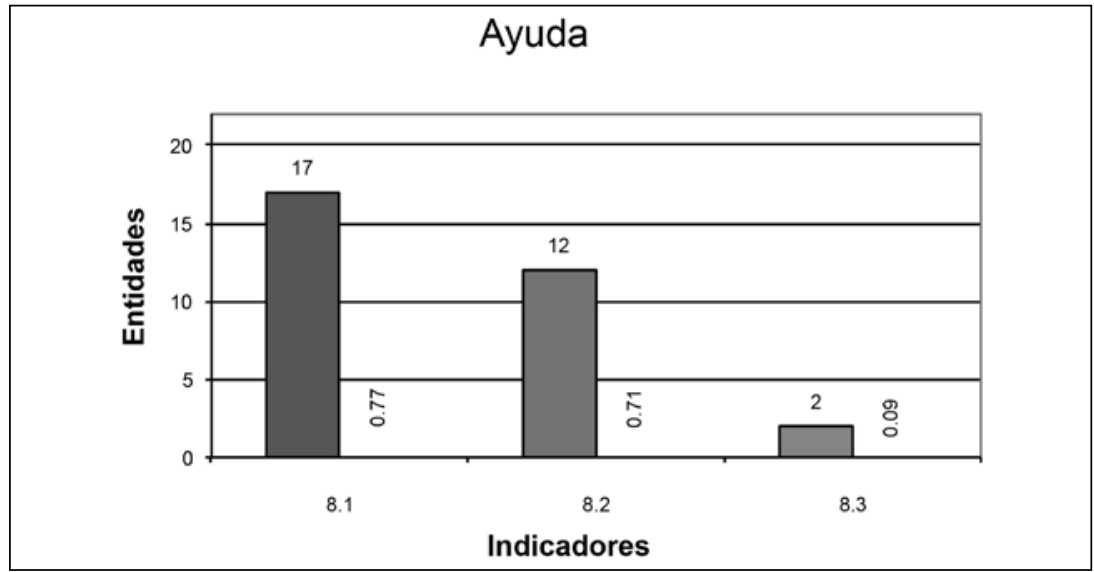

Fuente: elaboración propia

\section{Conclusiones}

A raíz de los resultados obtenidos, podemos afirmar que las cartotecas tienden a presentar su información como meros objetos digitales porque la mayoría no aportan otro valor añadido que no sea la visualización de los documentos. Existe diversidad en el uso que las diferentes cartotecas hacen en relación con los elementos y recursos propios e inherentes a la Arquitectura de la Información. Dentro de un ámbito o área, en el diseño de la página se ha de tener en cuenta que todas van a compartir elementos y estructuras comunes y la finalidad es que el usuario encuentre lo que busca. Preguntas tales como ¿qué distingue a una cartoteca de otra? o ¿cómo puedo diferenciar a una cartoteca de otra? encuentran su respuesta en la Arquitectura de la Información. Desde esta perspectiva, tan importante es el contenido que presentan estas entidades como la forma en que se muestra y es accesible al usuario.

Por su parte, la tendencia a la que se encaminan las cartotecas digitales con presencia en Internet debería ser facilitar las consultas a los diferentes usuarios que acuden generalmente a buscar información, así como el uso de elementos que les ayuden a satisfacer sus necesidades informativas. Resulta 
contradictorio, entonces, que algunos de los organismos que tienen presencia en redes europeas de colaboración no tengan su sitio web traducido a otros idiomas. Además, es de notar que las redes sociales no constituyan un recurso, aun con la importancia que tienen hoy en día como medios a través de los cuales se pueden hacer llegar los contenidos al usuario; lo mismo sucede con la sindicación de contenidos, por lo que se deberían de encaminar las actuaciones hacia estas vertientes. La dinámica actual conlleva el establecimiento de redes de colaboración o grupos de trabajo cuya finalidad principal es compartir y unificar el conocimiento.

\section{Bibliografía}

AENOR (2011), Papel. Papel cartográfico para usos generales, UNE 57048: 1971, Madrid: AENOR.

Blanco García, Ángel (2010), "Las cartotecas universitarias en España: un universo desconocido", trabajo presentado en IV Ibercarto, 28-29 de octubre de 2010, Valencia.

Caywood, Carolyn (1995), Library Selection Criteria for WWW Resour ces. Disponible en: http://www.keele.org.uk/lt/Internet/criteria.htm

Ciolek, T. M. (1996), "The Six Quests for The Electronic Grail: Current Approaches to Information Quality in WWW Resources", en Review Informatique et Statistique dans les Sciences bumaines, núm. 1-4. Disponible en: http://www.ciolek.com/PAPERS/six-ques ts1996.html

Codina, L. (2006), Metodología de análisis y evaluación de recursos digitales en linea: parámetros e indicadores. Disponible en: http://www. lluiscodina.com/metodos.htm

Fallas, J. (2003), Conceptos básicos de cartografía, Heredia, Costa Rica: Universidad Nacional. Disponible en: http://www.mapealo.com/ Costaricageodigital/Documentos/alfabetizacion/intro_carto.pdf

Felicísimo, Á. M. (1994), Modelos Digitales del Terreno: introducción y aplicaciones en las ciencias ambientales, Oviedo: Pentalfa. Disponible en: http://www.google.es/url? sa $=\mathrm{t} \& \mathrm{rct}=\mathrm{j} \& \mathrm{q}=\&$ esrc $=\mathrm{s} \& \mathrm{frm}=1$ $\&$ source $=$ web $\& c d=2 \& c a d=$ rja \&ved $=0$ CDQQFjAB \&url $=$ http $\% 3$ A\%2F\%2Fwww.researchgate.net\%2Fpublication\%2F232423519_ Modelos_digitales_del_terreno._Introduccin_y_aplicaciones_en_ las_ciencias_ambientales $\% 2$ Ffile\%2F79e41508a6f8c5c4c7.pdf\&ei

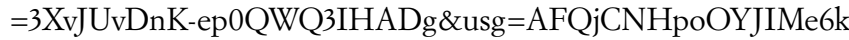
s4zHwezg6LC_z2Dag

Fernández Wyttenbach, A. y Bernabé Poveda, M. Á. (2011), "La cartoteca virtual: salvaguardia y accesibilidad al patrimonio documental cartográfico", en Revista PH, núm. 77, pp. 132-138. Disponible en: www.iaph.es/revistaph/index.php/revistaph/article/view/3120 
Grassian, E. (2008), Thinking Critically about Web 2.0 and Beyond. Disponible en :http://www.sscnet.ucla.edu/library/modules/Judge/CL ThinkWeb20.pdf

Hansen Albites, F. A. (2008), Apuntes de cartografía, Aguascalientes, México: Instituto Nacional de Estadística y Geografía. Disponible en: http://www.inegi.org.mx/inegi/spc/doc/INTERNET/Apuntes \%20de\%20cartograf\%C3\%ADa.pdf

Hassan Montero, Y. y Martín Fernández, F. J. (2011), "Guía de Evaluación Heurística de Sitios Web”, en No Solo Usabilidad, núm. 2. Disponible en: http://www.nosolousabilidad.com/articulos/heuris tica.htm

Herrero Rico, J. L. (2000), "Cartografía digital y Espeleología”, en Lapiaz, núm. 27, marzo, pp. 2-4. Disponible en: http://ocw.um.es/ cc.-sociales/deportes-de-aventura/material-de-clase-1/cartografiadigital-y-espeleologia-01.pdf

Instituto Geográfico de Venezuela Simón Bolívar (2011), Sistema cartográfico: Conceptos básicos: cartografía. Disponible en: http://sigot. geoportalsb.gob.ve/abrae_web/cartografia/

International Federation of Library Associations and Institutions (1987), ISBD (CM): International Standard Bibliographic Description for Cartographic Materials, Londres: IFLA. Disponible en: http:// www.ifla.org/files/assets/cataloguing/isbd/isbd-cm_1987.pdf

International Organization for Standardization (2003), Geographic information: Metadata. ISO 19115:2003, Ginebra: ISO.

Jiménez Piano, M. (2001), "Evaluación de sedes web”, en Revista española de Documentación Científica, vol. 24, núm. 4, pp. 405-432. Disponible en: http://redc.revistas.csic.es/index.php/redc/article /viewArticle/69

Líter Mayayo, C. (2012), Directorio de cartotecas y de colecciones cartográficas en instituciones españolas, Madrid: Biblioteca Nacional de España. Disponible en: http://www.bne.es/es/Colecciones/docs/ DirectorioCartotecas.pdf

Marín Hernández, J. J. y Vargas, H. (2010), “La cartografía histórica georreferenciada: un punto de encuentro en el análisis estadístico regional”, trabajo presentado en $X$ Congreso Centroamericano de Historia, 12-15 de julio de 2010, Nicaragua. Disponible en: http:// hcentroamerica.fcs.ucr.ac.cr/Contenidos/hca/cong/mesas/x_con greso/regional/cartografia-georeferenciada.pdf

ONU (Organización de las Naciones Unidas. Departamento de Asuntos Económicos y Sociales) (2000), Manual de sistemas de información geográfica y cartografía digital, Nueva York: Naciones Unidas. Disponible en: http://unstats.un.org/unsd/publication/SeriesF/Se riesF_79s.pdf

Nielsen, J. (1995), 10 usabilty beuristics for User Interface Design. Disponible en: http://www.nngroup.com/articles/ten-usability-heuristics/ 
Olsina, L. A. (1999), Metodología cuantitativa para la evaluación y comparación de la calidad de sitios web, tesis doctoral, Argentina, Universidad Nacional de la Plata, Facultad de Ciencias Exactas. Disponible en: http://di002.edv.uniovi.es/ cueva/investigacion/ tesis/WebsiteQEM.pdf

Pérez-Montoro Gutiérrez, M. (2010), Arquitectura de la información en entornos web, Gijón: Trea.

Reglas de Catalogación (1999), Madrid: Ministerio de Educación y Cultura, Centro de Publicaciones: Boletín Oficial del Estado. Disponible en: http://www.bne.es/es/Servicios/NormasEstandares/ ReglasDeCatalogacion/Docs/00000022.pdf

Rosenfeld, L. y Morville, P. (2002), Information Architecture for the World Wide Web, 2a. ed., California: O'Reilly Media.

Sánchez Maganto, A.; Nogueras Iso, J. y Ballari, D. (2008), "Normas Sobre Metadatos (ISO19115, ISO19115-2, ISO19139, ISO15836)”, en Mapping, núm. 123, enero, pp. 48-57. Disponible en: http://www. academia.edu/316388/Normas_Sobre_Metadatos_ISO19115_ISO 19115-2_ISO19139_ISO15836

Smith, A. (1997), "Testing the Surf: Criteria for evaluation of Internet Information Resources", en The Public-Access Computer Systems Review, vol. 8, núm. 3, pp. 5-23. Disponible en: http://www.vuw. ac.nz/staff/alastair_smith/Evaln/Index.Htm

Sulé Duesa, A.; Estivill Rius, A. y Gascón García, J. (2011), "Evaluación de las interfaces de consulta de las colecciones digitales patrimoniales españolas", en Anales de documentación, vol. 14, núm. 2, pp. 20-21. Disponible en: http://revistas.um.es/analesdoc/arti cle/viewFile/113931/124971

Weibel, S. L. y Koch, T. (2000), "The Dublin Core metadata initiative”, en D-lib magazine, vol. 6, núm. 12. Disponible en: http://mi rror.dlib.org/dlib/december00/weibel/12weibel.html

Zentai, L. (2012), “Does cartography still exist?”, en Proceedings AutoCarto 2012, 16-18 de septiembre de 2012, Columbus, Ohio. Disponible en: http://www.cartogis.org/docs/proceedings/2012/Zentai _AutoCarto2012.pdf 